\title{
Testing of minerals and industrial by-products as oxygen carriers for chemical-looping combustion in a circulating fluidized-bed $300 \mathrm{~W}$ laboratory reactor
}

\author{
Patrick Moldenhauer ${ }^{\mathrm{a}, *}$, Magnus Rydén ${ }^{\mathrm{a}}$, Anders Lyngfelt ${ }^{\mathrm{a}}$ \\ ${ }^{a}$ Department of Energy and Environment, Division of Energy Technology, Chalmers University of Technology, S-412 96 Göteborg, Sweden
}

\begin{abstract}
Chemical-looping combustion (CLC) is a promising technology for future energy production with inherent $\mathrm{CO}_{2}$ separation. One approach is to use minerals or industrial by-products as oxygen carriers to reduce the costs of the process. This study focuses on the investigation of two iron-based oxygen carriers, which were examined under continuous operation in a $300 \mathrm{~W}$ laboratory reactor. Ilmenite is an iron-titanium oxide mineral, whereas iron oxide scale (IOS) is obtained as a by-product from the rolling of sheet steel. Syngas was used as a fuel - pure and with steam addition to suppress the formation of solid carbon.

During the experiments the variables reactor temperature, fuel flow and air flow were changed. Furthermore the effect of steam addition to the fuel was investigated. Particle properties were compared over the span of $85 \mathrm{~h}$ of continuous operation for ilmenite and $37 \mathrm{~h}$ for IOS. The analysis is based on gas measurements from the actual CLC operation, but also on scanning electron microscopy, X-ray powder diffractometry and measurements of BET surface area and density.

With ilmenite oxygen carrier it was possible to achieve full conversion of syngas up to about $190 \mathrm{~W}_{\text {th }}$ fuel equivalent at $900{ }^{\circ} \mathrm{C}$. With design fuel flow of about $300 \mathrm{~W}_{\text {th }}$ at $900^{\circ} \mathrm{C}$ the combustion efficiency was above $98 \%$. There was almost no visible difference in reactivity of fresh activated particles and those used for $85 \mathrm{~h}$. Combustion efficiency up to $99 \%$ was achieved with IOS oxygen carrier at $900{ }^{\circ} \mathrm{C}$ and about $100 \mathrm{~W}_{\text {th }}$ fuel equivalent. At $300 \mathrm{~W}_{\text {th }}$ fuel equivalent and $900^{\circ} \mathrm{C}$ a combustion efficiency of only $90 \%$ could be reached.

Both oxygen carriers were operated for tens of hours, which allowed for a better understanding of lifetime behavior and other basic characteristics. Whereas ilmenite oxygen-carrier particles were mostly stable over the course of $85 \mathrm{~h}$ of experiments, a large fraction of IOS oxygen-carrier particles had disintegrated to fines after only $37 \mathrm{~h}$ of experiments. The gathered data indicates that both oxygen carriers could be an alternative to synthesized particles, though with more drawbacks for IOS than for ilmenite.
\end{abstract}

Keywords: chemical-looping combustion (CLC), circulating fluidized bed (CFB), $\mathrm{CO}_{2}$ capture, oxygen carrier, ilmenite, iron oxide scale, syngas

\section{Introduction}

Since the beginning of the Industrial Revolution, fossil fuels have become the main source of energy. During the combustion of coal or hydrocarbons, carbon dioxide $\left(\mathrm{CO}_{2}\right)$ is created and released in large quantities. $\mathrm{CO}_{2}$ in itself is neither hazardous nor toxic and therefore not considered to be a typical pollutant. Its danger lies in its long atmospheric residence time and its contribution to the greenhouse effect.

With a reduction of $\mathrm{CO}_{2}$ emissions, $\mathrm{CO}_{2}$ being the gas contributing the most to the anthropogenic greenhouse effect, much can be accomplished to counteract global climate change. This is why there is a strong need for new energy conversion technologies that do not emit carbon dioxide.

Carbon capture and storage (CCS) is a possibility to reduce $\mathrm{CO}_{2}$ emissions drastically while still being able to use fossil fuels. Although CCS processes are often associated with fossil fuel-based power generation, other applications are possible,

\footnotetext{
${ }^{*}$ Corresponding author. Telephone: +46(0)31-772 1469

Email address: patrick.moldenhauer@chalmers.se (Patrick Moldenhauer)
}

e.g. the production of carbon-free fuels. CCS involves the steps sequestration, transportation and storage of $\mathrm{CO}_{2}$. Underground storage is required to separate $\mathrm{CO}_{2}$ from the natural carbon cycle for the next millennia and possibly bind the $\mathrm{CO}_{2}$ permanently.

\subsection{Chemical-Looping Combustion}

Chemical-looping combustion (CLC) is a method of burning fuels with inherent sequestration of $\mathrm{CO}_{2}$. In the most commonly proposed CLC approach, particles are circulated between two interconnected reactors (air reactor and fuel reactor), with no gas leakage between the reactors. In the air reactor (AR) the particles are oxidized with air and in the fuel reactor (FR) reduced by fuel, before the cycle begins anew. As the oxygen carrier (OC) is circulated between air and fuel reactors, it transports the necessary combustion oxygen from the air to the fuel. Thus, air and fuel are never mixed, and after condensing the water, the stream of flue gases consists of nearly pure $\mathrm{CO}_{2}$. The inherent separation of the $\mathrm{CO}_{2}$ does not incur any direct energy penalty. A high efficiency, a high $\mathrm{CO}_{2}$-capture rate and the possibility of using different kinds of fuels suggest that CLC could be economically feasible and thus competitive. 


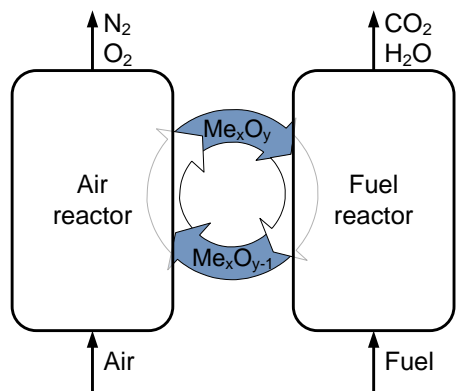

Figure 1: Schematic illustration of the chemical-looping combustion process

Figure 1 shows the basic design of a CLC system and illustrates the working principle. The reactions in the air and fuel reactors are expressed by reactions (1) and (2) respectively.

$$
\begin{array}{cc}
\text { AR: } & \mathrm{Me}_{x} \mathrm{O}_{y-1}+1 / 2 \mathrm{O}_{2} \longrightarrow \mathrm{Me}_{x} \mathrm{O}_{y} \\
\text { FR: } & (2 n+m) \mathrm{Me}_{x} \mathrm{O}_{y}+\mathrm{C}_{n} \mathrm{H}_{2 m} \longrightarrow \\
& (2 n+m) \mathrm{Me}_{x} \mathrm{O}_{y-1}+m \mathrm{H}_{2} \mathrm{O}+n \mathrm{CO}_{2}
\end{array}
$$

The oxidation of particles in the air reactor, as shown in reaction (1), is exothermic. The reducing reaction in the fuel reactor, as shown in reaction (2), can be either exothermic or endothermic, an outcome that depends on the oxygen carrier and the fuel used. With syngas as fuel, the reaction in the fuel reactor is exothermic for most oxygen carriers.

Since the oxygen carrier is chemically active and undergoes permanent mechanical stress due to abrasion and impact, it eventually needs to be replaced. Finding a cheap and durable oxygen carrier is a key factor. A good oxygen carrier needs to have high reduction and oxidation reaction rates, be non-toxic, available and reasonable cheap. One approach is to use industrial by-products, ores or minerals instead of synthetic oxygencarrier particles. Such particles need less preparation and are therefore cheaper.

The main characteristics of an oxygen carrier are:

- The oxygen transfer capacity $R_{o}$, i.e. the maximum mass fraction of oxygen that can be transferred by the oxygen carrier from air and fuel reactors per cycle; it needs to be sufficiently high in order to avoid large circulation rates.

- The reaction kinetics of an oxygen carrier determines the amount of bed inventory needed in air and fuel reactors. Larger bed inventories require bigger plants and increases the construction costs of a plant.

- High mechanical integrity is also important. Particle agglomeration, fragmentation and attrition cause either fluidization difficulties or loss of fines. The more particles become unusable, the higher the necessary make-up feed and therefore the operating expenses.

- Other important characteristics of a good oxygen carrier are cost, availability and its environmental impact. For example, a by- or waste product from another process, one that can be obtained with little or no expenses, would be well suited. Since it is possible that particle fines could be lost into the environment with the tail gas, oxygen carriers should preferably not be toxic, poisonous or hazardous in any way.

Overviews of developments of the different fields within CLC have been made by Lyngfelt et al. (2008) [1], Hossain and De Lasa (2008) [2], Fang et al. (2009) [3] and Lyngfelt (2011) $[4,5]$.

\section{Oxygen Carriers Examined}

\subsection{Ilmenite}

Ilmenite $\left(\mathrm{FeTiO}_{3}\right)$ is a mineral iron-titanium oxide. The term ilmenite is also used for ores that contain more or less of the said mineral. It is mined at several sites around the world. The sample tested here originates from Norway and were supplied by Titania A/S. It consist mainly of ilmenite $\left(\mathrm{FeTiO}_{3}\right)$ but also contains hematite $\left(\mathrm{Fe}_{2} \mathrm{O}_{3}\right)$. The particles were delivered as ground particles that needed only to be sieved in order to achieve suitable size ranges.

Ilmenite is not toxic, radioactive or hazardous in any known way. Its only environmental impact is from mining, thus possibly causing environmental damage by the mining in operation. Apart from grinding and physical beneficiation, ilmenite is an unprocessed mineral and cheap.

Fundamental research of the phase relations of ilmenite particles was done by den Hoed and Luckos [6].

When fresh ilmenite particles are heated up to $400{ }^{\circ} \mathrm{C}$ to $450{ }^{\circ} \mathrm{C}$ in air at ambient conditions for the first time, they are oxidized to $\mathrm{Fe}_{2} \mathrm{TiO}_{5}$ (pseudobrookite). As a result of the oxidization the particles gain mass. During the first oxidation / reduction cycles they become more porous and their reactivity increases, as was found by Leion et al. [7] and Adánez et al. [8]. The reason for the increasing reactivity is most likely due to the fact that the surface area more than quadruples [7], which also leads to an increase of the particle size and a decrease of the density. Those processes are responsible for clear changes in fuel conversion with fresh particles during the initial operational period. Particles that underwent just this initial period with increasing reactivity are referred to as freshly activated, which corresponds to ca. 20 cycles in a batch reactor.

Ilmenite particles have been investigated thoroughly in a batch fluidized-bed reactor with methane $\left(\mathrm{CH}_{4}\right)$, syngas $\left(\mathrm{CO} / \mathrm{H}_{2}\right)$ and solid fuels by Leion et al. [7, 9, 10]. Those experiments were followed by continuous cycle experiments in the $300 \mathrm{~W}$ laboratory reactor with natural gas (mostly methane $\mathrm{CH}_{4}$ and ethane $\mathrm{C}_{2} \mathrm{H}_{6}$ ) as fuel gas, by Rydén et al. [11]. The experiments described here were all run with syngas.

\subsection{Iron Oxide Scale}

Iron oxide scale (IOS) is a waste product from the steel industry. It is produced during the rolling of steel sheets. This material is available in large amounts and is cheap. 
X-ray powder diffractometry (XRD) by Leion et al. [10], showed that "fresh" and used IOS basically consist of $\mathrm{Fe}_{2} \mathrm{O}_{3}$ (hematite). This is the oxidized form of the material, which in the CLC process is reduced to $\mathrm{Fe}_{3} \mathrm{O}_{4}$ (magnetite). Further reduction to $\mathrm{FeO}$ (wüstite) or $\mathrm{Fe}$ (metallic iron) is possible, but inadvisable for two reasons. First, because complete fuel conversion to $\mathrm{CO}_{2}$ and $\mathrm{H}_{2} \mathrm{O}$ can thermodynamically not be reached anymore $[12,13]$. Second, because those phases are known to have a high tendency to form agglomerates [14-16].

Iron oxide scale is delivered as small scales in undefined size ranges. The material is fully oxidized but contaminated with oil. The first step to making this material usable as oxygen carrier is heat treatment to get rid of the oil. The downside to this procedure is that the particles partially agglomerate. In order to obtain particles in a suitable size range, it is necessary to grind the particles, sieve them and make a selection. The term fresh in the context of IOS particles means that the particles underwent this treatment but have not been in operation in any reducing or oxidizing process.

IOS particles have been investigated thoroughly in a batch fluidized-bed reactor with methane $\left(\mathrm{CH}_{4}\right)$ and syngas $\left(\mathrm{CO}+\mathrm{H}_{2}\right)$ as fuels by Leion et al. [10]. During those experiments IOS particles proved to have good conversion rates for both fuel types but failed to reach stable reactivity.

\section{Experimental Details}

\subsection{W laboratory Reactor}

A $300 \mathrm{~W}$ fluidized bed reactor system was used in the tests. The design was focused on compactness and its purpose is to assess rather small quantities of oxygen carrier, typically $100 \mathrm{~g}$ to $300 \mathrm{~g}$. It works with gaseous fuels. An illustration of the reactor, which was used for the experiments in this work, can be seen in Figure 2.

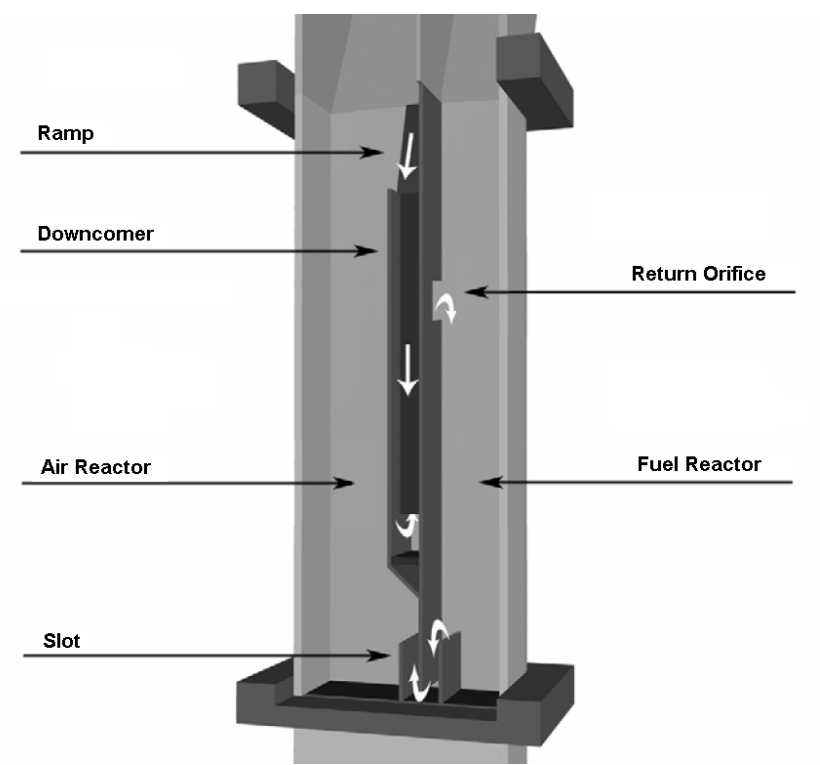

Figure 2: Schematic three-dimensional illustration of the improved $300 \mathrm{~W}$ laboratory reactor
Metal oxide particles $\left(\mathrm{Me}_{x} \mathrm{O}_{y-1}\right)$ enter the air reactor, where they are fluidized with air. During the fluidization reduced metal oxide particles are oxidized according to reaction (1). The fluidization velocity in the air reactor is high enough to create a circulating fluidized bed: while new particles are constantly fed to the bottom of the particle bed, particles at the top are accelerated upwards and leave the bed. The particle-gas mixture is then separated: the oxygen depleted air is returned to the atmosphere, whereas the metal oxide particles are transported through the upper loop seal (downcomer) to the fuel reactor. There, the metal particles are reduced by the fuel, which is also used to fluidize the particles. The reduced particles then pass through the lower loop seal (slot) and return to the air reactor, where the whole cycle starts over again.

Owing to the small thermal output, the heat of reaction is not enough to grant a sufficiently high temperature, typically $750{ }^{\circ} \mathrm{C}$ to $950{ }^{\circ} \mathrm{C}$. The reactor is therefore encased in an electric furnace.

\subsection{Ilmenite Experiments}

The reactor was initially filled with $270 \mathrm{~g}$ of ilmenite particles in the size range of $125 \mu \mathrm{m}$ to $180 \mu \mathrm{m}$. The particle mass is primarily determined by the bed volume that fits into the reactor and the particle density. Syngas, with $50 \mathrm{vol} \% \mathrm{H}_{2}$ and $50 \mathrm{vol} \%$ $\mathrm{CO}$, was used as fuel.

First, it was investigated whether the particles showed stable behavior in an extended time test with constant settings, see Base 1 in Table 1. The fuel flow was set to a level where full conversion of the fuel was just not reached anymore.

The first part of the series consisted of $31 \mathrm{~h}$ of operation with fuel and is summarized in Table 1. Over the course of this series the particle properties changed significantly. Most of the change is believed to happen during the initial period of fuel addition: During the first $3 \mathrm{~h}$ of continuous oxidization and reduction the oxygen carrier's reactivity increased drastically until stable levels were reached.

Table 1: Ilmenite test series part 1 - base parameters and settings for each test with fresh ilmenite particles

\begin{tabular}{|c|c|c|c|c|}
\hline $\begin{array}{l}\text { Test } \\
\text { number }\end{array}$ & $\begin{array}{c}U_{\mathrm{FR}} \\
\left(\mathrm{L}_{\mathrm{n}} / \mathrm{min}\right)\end{array}$ & $\begin{array}{c}U_{\mathrm{AR}} \\
\left(\mathrm{L}_{\mathrm{n}} / \mathrm{min}\right)\end{array}$ & $\begin{array}{l}T_{\mathrm{FR}} \\
\left({ }^{\circ} \mathrm{C}\right)\end{array}$ & $\begin{array}{c}\text { Corresponding } \\
\text { power }(\mathrm{W})\end{array}$ \\
\hline Base 1 & 1.63 & 6.7 & 900 & 320 \\
\hline I1.1 & $0.77-1.73$ & 6.7 & 900 & $150-340$ \\
\hline $\mathrm{I} 1.2$ & $0.77-1.54$ & 6.7 & 750 & $150-300$ \\
\hline I1.3 & $0.77-1.54$ & 6.7 & 800 & $150-300$ \\
\hline I1.4 & $0.77-1.54$ & 6.7 & 850 & $150-300$ \\
\hline I1.5 & $0.77-1.54$ & 6.7 & 950 & $150-300$ \\
\hline
\end{tabular}

a total of $0.42 \mathrm{~L} / \mathrm{min}$ argon was added to the particle locks

After this first part of the test series the reactor was opened and the particles were visually examined, weighed and sieved. The density of the particles was reduced to half that of fresh particles, and the particles had grown in size, see section 5.1 for details. The decrease in particle density caused an increase in bed height in the reactor, i.e. the reactor did not operate within design conditions any more. Hence, half the initial bed mass 
$(135 \mathrm{~g}$ instead of $270 \mathrm{~g}$ ) with particles in the size range of $90 \mu \mathrm{m}$ to $250 \mu \mathrm{m}$ was put back into the reactor for a second series of tests.

The second part of the series lasted for about $27 \mathrm{~h}$, during which problems concerning defluidization were encountered regularly. Simultaneously, some indications in the measurements suggested deposition of solid carbon in the hot part of the fuel line, close to the reactor. Both problems were solved by adding steam to the fuel. Different amounts of steam were added to the fuel until a stable setting was found. However, other than new base parameters, no usable data could be produced during this part of the experiments.

The third and final part of the experiment series lasted another $27 \mathrm{~h}$. Starting from the new base parameters, which were found earlier, see Base in Table 2, a variation of the parameters fuel flow, temperature and air flow was investigated. The settings used for this test series is shown in Table 2, I2.1 - I2.5. All settings during those experiments included steam addition as a constant percentage of fuel.

Table 2: Ilmenite test series part 2 - base parameters and settings for each test with used ilmenite particles

\begin{tabular}{|c|c|c|c|c|}
\hline $\begin{array}{l}\text { Test } \\
\text { number }\end{array}$ & $\begin{array}{c}U_{\mathrm{FR}}^{1} \\
\left(\mathrm{~L}_{\mathrm{n}} / \mathrm{min}\right)\end{array}$ & $\begin{array}{c}U_{\mathrm{AR}} \\
\left(\mathrm{L}_{\mathrm{n}} / \min \right)\end{array}$ & $\begin{array}{l}T_{\mathrm{FR}} \\
\left({ }^{\circ} \mathrm{C}\right)\end{array}$ & $\begin{array}{c}\text { Corresponding } \\
\text { power }(\mathrm{W})\end{array}$ \\
\hline Base 2 & 0.53 & 6.7 & 900 & 100 \\
\hline I2.1 & $0.53-0.79$ & 6.7 & 750 & $100-155$ \\
\hline $\mathrm{I} 2.2$ & $0.53-0.66$ & 6.7 & 800 & $100-130$ \\
\hline $\mathrm{I} 2.3$ & $0.53-0.66$ & 6.7 & 850 & $100-130$ \\
\hline $\mathrm{I} 2.4$ & $0.53-1.06$ & 6.7 & 900 & $100-205$ \\
\hline $\mathrm{I} 2.5$ & 0.53 & $5.8-9.6$ & 900 & 100 \\
\hline
\end{tabular}

a total of $0.49 \mathrm{~L}_{\mathrm{n}} / \mathrm{min}$ argon was added to the particle locks

1 additionally: $1 / 6$ steam $(5 / 6$ syngas $+1 / 6$ steam $)$

Altogether, about $85 \mathrm{~h}$ of experiments were conducted with the same ilmenite particles, i.e. $31 \mathrm{~h}+27 \mathrm{~h}+27 \mathrm{~h}$.

\subsection{Iron Oxide Scale Experiments}

The experimental procedure resembles that of the ilmenite particles to a large extent. Steam was added to the fuel from the very beginning.

The IOS particles had a high tendency to form hard agglomerates at the bottom of the fuel reactor. These agglomerates typically covered the whole area of the fuel reactor just above the gas distributor plate and had a few gas channels that still allowed the fuel gas to enter the reactor. When such agglomerates formed, the process became unstable. The reactor then had to be opened and the agglomerate had to be removed by mechanical force. Since the agglomerated particles could not be used any further, they had to be replaced by fresh material, which in turn made a study of the particles difficult.

During the first $17 \mathrm{~h}$ of operation (two charges of IOS particles), no usable data could be obtained at all. Only with the third charge of particles, a series of tests with varying parameters could be performed. And even after running the whole test series successfully, some minor agglomeration was found in the fuel reactor, which covered the whole width, but only a few millimetres high and below the edge of the slot wall. Hence, it is believed that this agglomeration, regardless of when it formed, did not affect the CLC process significantly.

Table 3: Base parameters and settings for each test of the test series with IOS particles

\begin{tabular}{|c|c|c|c|c|}
\hline $\begin{array}{l}\text { Test } \\
\text { number }\end{array}$ & $\begin{array}{c}U_{\mathrm{FR}} \\
\left(\mathrm{L}_{\mathrm{n}} / \mathrm{min}\right)\end{array}$ & $\begin{array}{c}U_{\mathrm{AR}} \\
\left(\mathrm{L}_{\mathrm{n}} / \min \right)\end{array}$ & $\begin{array}{l}T_{\mathrm{FR}} \\
\left({ }^{\circ} \mathrm{C}\right)\end{array}$ & $\begin{array}{c}\text { Corresponding } \\
\text { power }(\mathrm{W})\end{array}$ \\
\hline Base & 1.06 & 6.7 & 900 & 205 \\
\hline G1 & $0.53-1.86$ & 6.7 & 900 & $100-360$ \\
\hline $\mathrm{G} 2$ & 1.06 & $3.8-9.6$ & 900 & 205 \\
\hline G3 & $0.53-1.59$ & 6.7 & 800 & $100-310$ \\
\hline G4 & $0.53-1.59$ & 6.7 & 850 & $100-310$ \\
\hline G5 & $0.53-1.59$ & 6.7 & 950 & $100-310$ \\
\hline
\end{tabular}

a total of $0.42 \mathrm{~L}_{\mathrm{n}} / \mathrm{min}$ argon was added to the particle locks "G" stands for the Swedish term of IOS: Glödskal

The series of experiments, summarized in Table 3, was performed over a period of $14 \mathrm{~h}$. After that, the influence of steam addition was investigated for another $6 \mathrm{~h}$.

\section{Data Evaluation}

Prior to analysis, the flue gases from the reactor pass through a gas cooler, a particle filter and a water trap. The dry-gas concentrations thus obtained are recorded continuously by a set of gas analyzers. Carbon monoxide $(\mathrm{CO})$ and carbon dioxide $\left(\mathrm{CO}_{2}\right)$ are measured with infrared analyzers while the oxygen $\left(\mathrm{O}_{2}\right)$ concentration is measured with a paramagnetic sensor. Additionally, the dry-gas concentration of $\mathrm{CO}$, nitrogen $\left(\mathrm{N}_{2}\right)$ and hydrogen $\left(\mathrm{H}_{2}\right)$ can be measured with a gas chromatograph. The inlet flows are controlled by individual mass flow controllers for each gas line.

One method of rating the gas conversion of carbonic combustion processes is through the $\mathrm{CO}_{2}$ gas yield, see equation (3). A similar expression is used for the $\mathrm{H}_{2} \mathrm{O}$ yield of hydrogen combustion, see equation (4).

$$
\begin{gathered}
\gamma_{\mathrm{CO} 2}=\frac{x_{\mathrm{CO} 2}}{x_{\mathrm{CO}}+x_{\mathrm{CO} 2}}=1-\frac{x_{\mathrm{CO}}}{x_{\mathrm{CO}}+x_{\mathrm{CO} 2}} \\
\gamma_{\mathrm{H} 2 \mathrm{O}}=\frac{y_{\mathrm{H} 2 \mathrm{O}}}{y_{\mathrm{H} 2}+y_{\mathrm{H} 2 \mathrm{O}}}=1-\frac{y_{\mathrm{H} 2}}{y_{\mathrm{H} 2}+y_{\mathrm{H} 2 \mathrm{O}}}
\end{gathered}
$$

Since the $\mathrm{H}_{2}$ concentration needs to be calculated and the measured concentrations are based on dry-gas, equation (4) is of limited practical value. In order to change this, the hydrogento-carbon ratio is introduced.

For a given fuel mix hydrogen and carbon occur in a fixed ratio $(\mathrm{H} / \mathrm{C})_{\mathrm{fm}}$. If no solid carbon is formed in the fuel line or in the reactor, this ratio applies for the whole fuel reactor. For syngas ( $50 \mathrm{vol} \% \mathrm{H}_{2}+50 \mathrm{vol} \% \mathrm{CO}$ ) this ratio is 2 , see equation (5). The denominator in equation (4) is then substituted and the $\mathrm{H}_{2} \mathrm{O}$ gas yield rewritten according to equation (6). 


$$
\begin{aligned}
(H / C)_{\mathrm{fm}} & =\frac{2 \cdot y_{\mathrm{H} 2 \mathrm{O}}+2 \cdot y_{\mathrm{H} 2}}{y_{\mathrm{CO}}+y_{\mathrm{CO} 2}} \\
\text { for }(H / C)_{\mathrm{fm}} & =2 \Rightarrow y_{\mathrm{H} 2 \mathrm{O}}+y_{\mathrm{H} 2}=y_{\mathrm{CO}}+y_{\mathrm{CO} 2} \\
\gamma_{\mathrm{H} 2 \mathrm{O}} & =1-\frac{y_{\mathrm{H} 2}}{y_{\mathrm{CO}}+y_{\mathrm{CO} 2}}=1-\frac{x_{\mathrm{H} 2}}{x_{\mathrm{CO}}+x_{\mathrm{CO} 2}}
\end{aligned}
$$

Syngas and most other fuels consist of mixed species. Therefore, an efficiency, which combines both gas yields, is more significant. The approach is thus to weight both conversions with their individual lower heating value and incorporate them into one equation, the combustion efficiency $\gamma_{\mathrm{eff}}$, see equation (7).

$$
\begin{aligned}
\gamma_{\mathrm{eff}} & =1-\frac{\left(1-\gamma_{\mathrm{CO} 2}\right) \cdot H_{\mathrm{i} 2, \mathrm{CO}}+\left(1-\gamma_{\mathrm{H} 2 \mathrm{O}}\right) \cdot H_{\mathrm{i} 2, \mathrm{H} 2}}{H_{\mathrm{i} 2, \mathrm{CO}}+H_{\mathrm{i} 2, \mathrm{H} 2}} \\
& =1-\frac{x_{\mathrm{CO}} \cdot H_{\mathrm{i} 2, \mathrm{CO}}+x_{\mathrm{H} 2} \cdot H_{\mathrm{i} 2, \mathrm{H} 2}}{\left(x_{\mathrm{CO}}+x_{\mathrm{CO} 2}\right) \cdot\left(H_{\mathrm{i} 2, \mathrm{CO}}+H_{\mathrm{i} 2, \mathrm{H} 2}\right)}
\end{aligned}
$$

One fact that is not taken into account by equation (7) are gas leakages between the reactor halves. Leakage of fuel from fuel to air reactor reduces the overall $\mathrm{CO}_{2}$ capture efficiency. However, it does not significantly affect the reactions in the fuel reactor and the analysis. Dilution on the other hand, i.e. air leaking from air reactor to fuel reactor, might cause an increase in the combustion efficiency, since more oxygen is made available in the fuel reactor. The impact of dilution strongly depends on where it happens. Dilution of the flue gases above the bed, i.e. via the upper loop seal, would cause a much bigger error than a dilution of the lower bed, i.e. via the lower loop seal. A leakage of about $4 \%$ of $U_{\mathrm{FR}, \mathrm{in}}$, a dilution of about $1 \%$ of $U_{\mathrm{FR}, \text { in }}$ and a dilution from the particle locks of about $50 \%$ of $U_{\mathrm{PL}}$ are characteristic values of the reactor. Those values were determined in a separate leakage investigation and are estimated during operation based on $\mathrm{N}_{2}$ measurements in the fuel reactor (GC) and $\mathrm{CO}_{2}$ measurements in the air reactor (IR). Furthermore it was found out that dilution occurs almost completely via the lower particle lock. $1 \%$ of $U_{\mathrm{FR}, \text { in }}$ corresponds to $0.21 \%$ of $\mathrm{O}_{2}$ or the conversion of $0.4 \%$ of incoming fuel flow. If this oxygen reacts either with the oxygen carrier or with the fuel in the lower part of the fuel reactor, it is not likely to have a significant effect on the total conversion. The effects of internal leakages can thus be summarized to be negligible.

Except for hydrogen concentration the combustion efficiency $\gamma_{\text {eff }}$ consists only of measured or physical values. The hydrogen content can be estimated if it is assumed that the gas inside the fuel reactor is at thermodynamic equilibrium, based on the water-gas shift reaction. Under this assumption equation (9) is valid and can, together with equation (8), be solved for the hydrogen concentration. The hydrogen-to-carbon ratio that is used for the equilibrium calculation includes possible steam addition to the fuel. For a mixture of $1 / 6$ steam and $5 / 6$ syngas, as was used here, $(\mathrm{H} / \mathrm{C})_{\mathrm{FR}}$ is 2.8 .

$$
\begin{aligned}
(H / C)_{\mathrm{FR}} & =\frac{2 \cdot y_{\mathrm{H} 2 \mathrm{O}}+2 \cdot y_{\mathrm{H} 2}}{y_{\mathrm{CO}}+y_{\mathrm{CO} 2}} \\
K_{\mathrm{wgs}} & =\frac{y_{\mathrm{CO} 2, \mathrm{FR}} \cdot y_{\mathrm{H} 2, \mathrm{FR}}}{y_{\mathrm{CO}, \mathrm{FR}} \cdot y_{\mathrm{H} 2 \mathrm{O}, \mathrm{FR}}}
\end{aligned}
$$

One possibility to rate an oxygen carrier is through the oxygen transfer capacity $R_{o}$. It expresses the highest theoretic mass change between the state of complete oxidization $\left(m_{\mathrm{OC}, \mathrm{ox}}\right)$ and full reduction $\left(m_{\mathrm{OS}, \mathrm{red}}\right)$, see equation $(10)$.

$$
R_{o}=\frac{m_{\mathrm{OC}, \mathrm{ox}}-m_{\mathrm{OC}, \mathrm{red}}}{m_{\mathrm{OC}, \mathrm{ox}}}
$$

The difference between the oxygen carrier's reduced form, $\mathrm{FeTiO}_{3}$ (ilmenite), and its most oxidized form, $\mathrm{Fe}_{2} \mathrm{TiO}_{5}$ and $\mathrm{TiO}_{2}$ (pseudobrookite and rutile), corresponds to an oxygen transfer capacity of $5 \%$. The theoretical $R_{o}$ for IOS particles is $3.3 \%$ and corresponds to the reduction of iron oxide particles from $\mathrm{Fe}_{2} \mathrm{O}_{3}$ (hematite) to $\mathrm{Fe}_{3} \mathrm{O}_{4}$ (magnetite).

The oxygen transfer capacity permits the evaluation of the basic suitability of an oxygen carrier. However, that does not mean that it is always desirable to reach that value. Previous experiments by Cho et al. [17] and Leion et al. [9] have shown that if the oxygen carrier is reduced until almost reaching the maximum reduction, the combustion efficiency deteriorates significantly. To describe the actual reduction, two terms are usually used in the CLC literature; the degree of oxidation $X$ and the degree of mass-based conversion $\omega$. They are defined according to equations (11) and (12).

$$
\begin{aligned}
X & =\frac{m_{O C}-m_{O C, \text { red }}}{m_{O C, o x}-m_{O C, \text { red }}} \\
\omega & =\frac{m_{O C}}{m_{O C, o x}}=1+R_{o} \cdot(X-1)
\end{aligned}
$$

The actual mass of the oxygen carrier $\left(m_{O C}\right)$ cannot be determined during the operation of the $300 \mathrm{~W}$ reactor. Instead, bed height in the fuel reactor and bulk density of the particles are measured when the reactor is opened, which in turn allows for the estimation of the bed mass. Hence, the only way to ascertain the actual reduction is to infer it indirectly from how much oxygen is needed to oxidize the oxygen carrier when the fuel flow is shut off, i.e. at the end of each experiment.

It is possible to calculate the oxygen carrier circulation $\dot{m}_{\mathrm{OC}}$, see equation (13), as a function of $\omega$, the oxygen consumed in the air reactor $\Delta \dot{m}_{\mathrm{O} 2, \mathrm{AR}}$ and the degree of mass-based conversion in the air reactor $\omega_{\mathrm{AR}}$. Here, $\omega$ is derived from reoxidation data, see equation (12), and oxygen consumption in the air reactor $\Delta \dot{m}_{\mathrm{O} 2, \mathrm{AR}}$ from continuous operation. If it is assumed that the oxygen carrier is completely oxidized in the air reactor, then $\omega_{\mathrm{AR}}$ in equation (13) becomes 1 . Hence, the oxygen carrier circulation can be estimated for the one air reactor air flow, which was used prior to reoxidation.

$$
\dot{m}_{\mathrm{OC}}=\frac{\omega_{\mathrm{AR}} \cdot \Delta \dot{m}_{\mathrm{O} 2, \mathrm{AR}}}{\Delta \omega}=\frac{\omega_{\mathrm{AR}}{ }^{1} \cdot \Delta \dot{m}_{\mathrm{O} 2, \mathrm{AR}}}{\omega_{\mathrm{AR}}{ }^{1}-\omega}
$$


In addition to the analysis of the in situ data, XRD and density measurements were performed and the BET surface area of the particles was measured by the method of gas adsorption.

\section{Results and Discussion}

\subsection{Ilmenite}

The processing of data is explained by using the first $160 \mathrm{~min}$ of operation as an example. During this initial phase the ilmenite oxygen carrier was reduced for the first time. This phase is especially interesting since the reactivity of the ilmenite particles increased considerably. Figure 3 shows this phase.

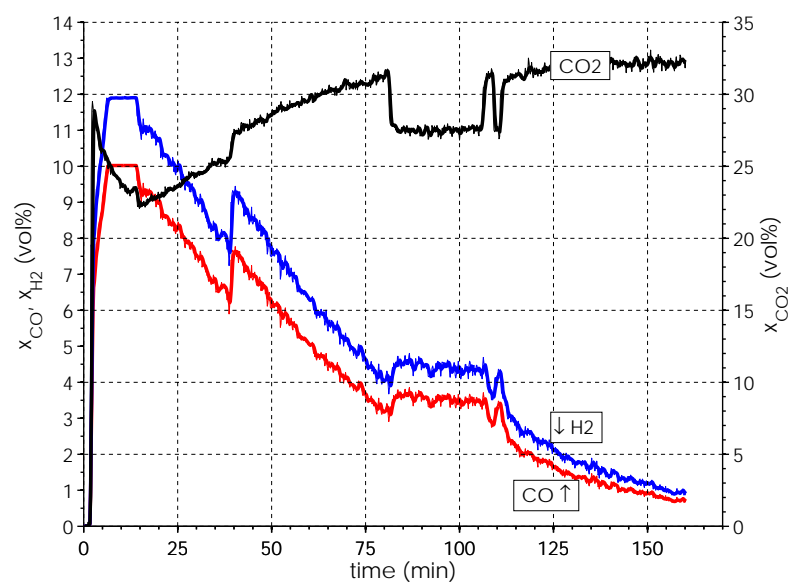

(a) Dry-gas concentrations

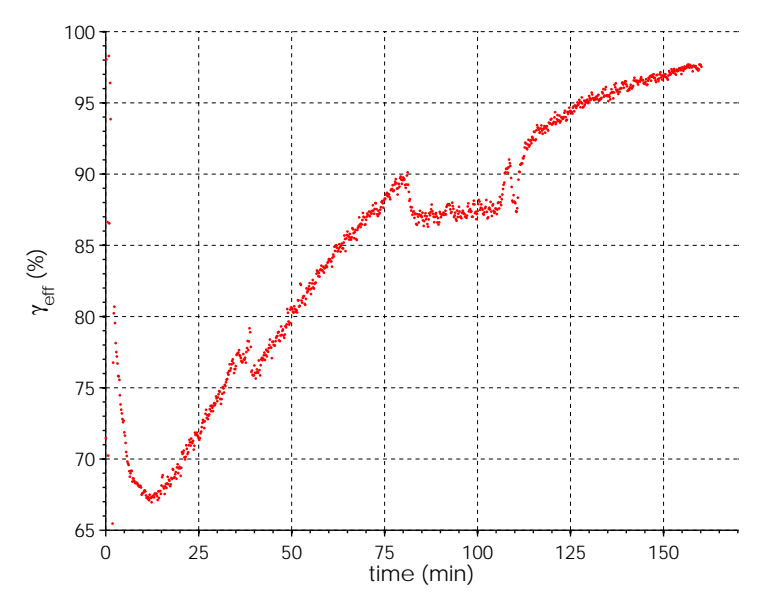

(b) Combustion efficiency

Figure 3: Measurements during the initial operational phase with ilmenite oxygen-carrier particles

During this initial phase is not only the fuel gas led to the fuel reactor, but also a flow of inert gas. The additional flow ensures that, despite the low fuel flow, a sufficient amount of gas gets into the fuel reactor to fluidize the particles.

After about $13 \mathrm{~min}$ the fuel flow was reduced. This was done, because the $\mathrm{CO}$ concentration went beyond the measuring range of the instrument. As the particles became more reactive, the $\mathrm{CO}$ concentration fell back into the measurable range and the fuel flow was switched back to the original level. This caused a slight drop in the combustion efficiency at about $38 \mathrm{~min}$, since temporarily more fuel gas passed through the reactor without reacting. Henceforward, the efficiency increased continuously until the circulation partly collapsed at about $80 \mathrm{~min}$. After the circulation was re-established through mechanical stimulation, increasingly more fuel was converted into $\mathrm{CO}_{2}$ and $\mathrm{H}_{2} \mathrm{O}$, see Figure $3 \mathrm{a}$, and the combustion efficiency increased steadily.

Table 4 illustrates what happened to the structure of the particles at the microscopic level. Even though the properties were determined after the first $31 \mathrm{~h}$, most of the changes are believed to have happened during the first hours of CLC operation, when the reactivity increased considerably, as shown in Figure 3.

The most drastic change was the reduction of the density of the particles. Most of the particles grew in size and only a minor amount decayed into fines. It cannot be said with certainty how high the fraction of particles leaving the system was, because of the mass gain of the fresh particles due to oxidation. The particles that are blown out of the system with the gases are usually mostly fines, i.e. $<45 \mu \mathrm{m}$. It is believed that $2 \%$ to $7 \%$ of the mass of the bed escaped from the system in this way.

Even though the properties of the particles changed significantly, they neither formed big agglomerates nor did they decay into fines or dust. This suggests that the particles are structurally stable - at least during the first $31 \mathrm{~h}$.

During the subsequent $54 \mathrm{~h}$ of operation about $19 \%$ of the mass of the bed was lost. This share is more than twice as high as before. But then, the total operational time was almost triple, which caused more wear and tear on the particles than during the first part of the experiment series. The size distribution of the particles of batch 2 was narrowed down, see Table 4. The relative amount of particles in the size range of $125 \mu \mathrm{m}$ to $180 \mu \mathrm{m}$ increased, whereas it decreased for most of the other size ranges.

Figure 4 shows scanning electron microscope (SEM) images of the ilmenite oxygen carrier at different points in the experimental series. The structural changes of the particles during the initial operation time can be seen clearly.

Table 5 shows an X-ray powder diffractometry (XRD) of ilmenite particles at the different stages in the experimental series. Fresh particles are thus in a reduced state $\left(\mathrm{FeTiO}_{3}\right)$ with some hematite $\left(\mathrm{Fe}_{2} \mathrm{O}_{3}\right)$. There is no visible difference between the particles after $31 \mathrm{~h}$ and $85 \mathrm{~h}$. The oxidized particles consist of $\mathrm{Fe}_{2} \mathrm{TiO}_{5}$ (pseudobrookite), $\mathrm{TiO}_{2}$ (rutile) and $\mathrm{Fe}_{2} \mathrm{O}_{3}$ (hematite).

Over the course of the $85 \mathrm{~h}$ of continuous oxidation and reduction a slight reduction of the oxygen carrier's reactivity was noticed. The mechanism that is believed to be responsible for the degrading of the particles is that oxidation processes cause a migration of iron species $\mathrm{Fe}^{3+}$ and $\mathrm{Fe}^{2+}$ to the surface, where they form an iron-rich layer $[8,18,19]$. The diffusion of $\mathrm{O}^{2-}$ anions through the iron-rich layer, as in case of continuous oxidation/reduction of the particle core, is slower than the oxidation/reduction of the iron-rich layer. A limited residence time of the oxygen carrier in air reactor and fuel reactor, i.e. oxidizing and reducing atmospheres, is most likely not sufficient for a complete oxidation / reduction of both particle core and ironrich shell. Once an iron-rich shell is formed, ilmenite oxygen 
Table 4: Ilmenite oxygen-carrier particle properties of fresh material, after $31 \mathrm{~h}$ and after $85 \mathrm{~h}$ of operation

\begin{tabular}{|c|c|c|c|c|c|}
\hline & \multicolumn{2}{|c|}{ Batch 1: $0-31 \mathrm{~h}$} & \multicolumn{2}{|c|}{ Batch 2: $31-85 \mathrm{~h}$} \\
\hline & & $\begin{array}{c}\text { Fresh } \\
\text { particles }\end{array}$ & $\begin{array}{c}\text { Recovered } \\
\text { particles }\end{array}$ & $\begin{array}{l}\text { Inserted } \\
\text { particles }\end{array}$ & $\begin{array}{c}\text { Recovered } \\
\text { particles }\end{array}$ \\
\hline \multirow{3}{*}{\multicolumn{2}{|c|}{$\begin{array}{l}\text { Color } \\
\text { Total bed mass }(\mathrm{g}) \\
\text { Bulk density }\left(\mathrm{g} / \mathrm{cm}^{3}\right)\end{array}$}} & dark gray & brown & brown & brown \\
\hline & & 270 & 264 & 135 & 110 \\
\hline & & 2.40 & 1.22 & 1.22 & 1.54 \\
\hline \multirow{7}{*}{ 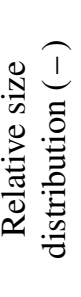 } & $45-90 \mu \mathrm{m}$ & 0 & 0.002 & 0 & 0.005 \\
\hline & $90-125 \mu \mathrm{m}$ & 0 & 0.030 & 0.030 & 0.104 \\
\hline & $125-180 \mu \mathrm{m}$ & 1 & 0.433 & 0.437 & 0.672 \\
\hline & $180-212 \mu \mathrm{m}$ & 0 & 0.324 & 0.327 & 0.158 \\
\hline & $212-250 \mu \mathrm{m}$ & 0 & 0.204 & 0.206 & 0.046 \\
\hline & $250-355 \mu \mathrm{m}$ & 0 & 0.004 & 0 & 0.005 \\
\hline & $>355 \mu \mathrm{m}$ & 0 & 0.002 & 0 & 0.011 \\
\hline
\end{tabular}

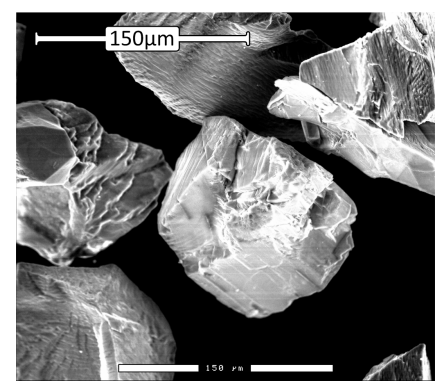

(a) Fresh particles

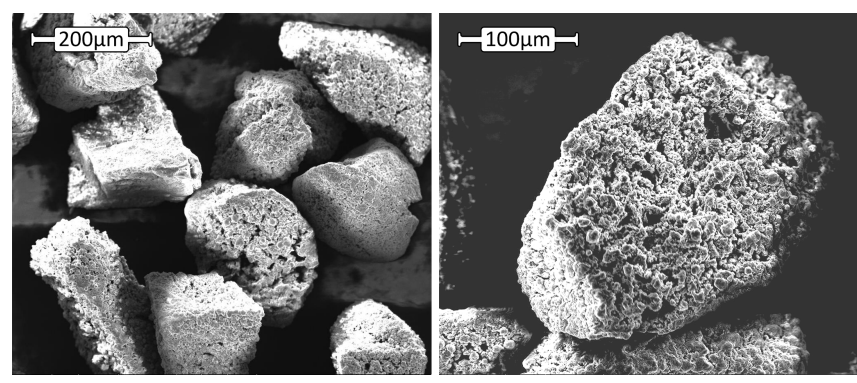

(b) After $31 \mathrm{~h}$

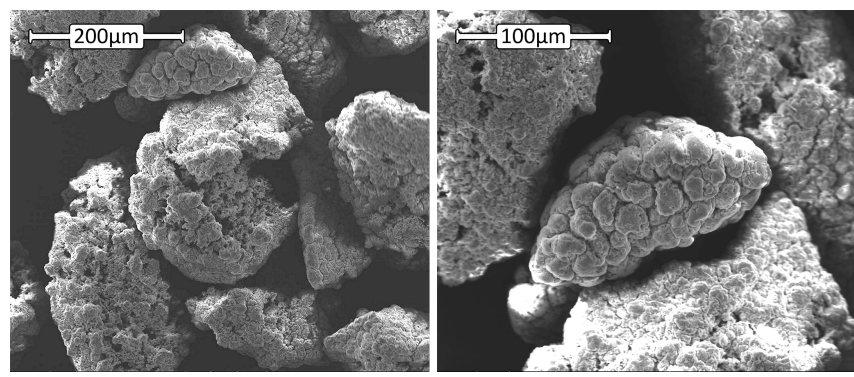

(c) After $85 \mathrm{~h}$

Figure 4: SEM images of fresh and used ilmenite oxygen-carrier particles

carrier might behave as an iron-based particle with an near inert core instead of a homogeneous iron-titanium oxide.

The relative amount of oxygen that can be carried and released by an iron-based oxygen carrier with the oxide system
$\mathrm{Fe}_{2} \mathrm{O}_{3} / \mathrm{Fe}_{3} \mathrm{O}_{4}$ corresponds to $3.3 \%$ of its mass. A homogeneous ilmenite oxygen carrier on the other hand has the ability to carry and release $5 \%$. Hence the iron migration is believed to cause a loss in oxygen transfer capacity. On the other hand, Jerndal et al. found that iron-based oxygen carriers generally have higher conversion rates of $\mathrm{H}_{2}$ and $\mathrm{CO}$ than mineral ilmenite [20]. Thermodynamic equilibrium calculations show that the oxide system $\mathrm{Fe}_{2} \mathrm{O}_{3} / \mathrm{Fe}_{3} \mathrm{O}_{4}$ allows for a complete conversion of syngas to $\mathrm{CO}_{2}$ and $\mathrm{H}_{2} \mathrm{O}$ [13]. Thermodynamic calculations for ilmenite oxygen carrier, however, are difficult to make due to structural changes of the particles. The observations made in this study suggest that the negative effects slightly outweigh the positive ones in the long term.

Table 5: XRD analysis of ilmenite oxygen-carrier particles

\begin{tabular}{lll}
\hline Particles & & Indicated phases \\
${$\cline { 1 - 1 }$}{ }^{1} }$ & & ilmenite $\left(\mathrm{FeTiO}_{3}\right)$, hematite $\left(\mathrm{Fe}_{2} \mathrm{O}_{3}\right)$ \\
After 31 h & & $\mathrm{Fe}_{2} \mathrm{TiO}_{5}$ (pseudobrookite), \\
& $\mathrm{Fe}_{2} \mathrm{O}_{3}$ (hematite), $\mathrm{TiO}_{2}$ (rutile) \\
After 85 h & $\begin{array}{ll}\mathrm{Fe}_{2} \mathrm{TiO}_{5} \text { (pseudobrookite), } \\
\mathrm{Fe}_{2} \mathrm{O}_{3} \text { (hematite), } \mathrm{TiO}_{2} \text { (rutile) }\end{array}$ \\
\hline 1 from [9] &
\end{tabular}

The two most evident changes between the initial period ( $270 \mathrm{~g}$ ilmenite) and the phase in the end (135 $\mathrm{g}$ ilmenite with steam addition) are that the conversion worsened and that the variance of the measured concentrations increased. Both can be ascribed to the reduction of bed heights to the design level. In order to achieve full fuel conversion a certain amount of bed mass compared to fuel in the fuel reactor is necessary. Bubbles, which are an integral element of a fluidized bed, will cause higher fluctuations in a bed with low bed height than in one with design bed height and thus cause higher variance.

Figure 5 shows those experiments where the fuel flow is varied while all other variables are held constant.

When the fuel flow is increased, the combustion efficiency for the CLC process with $135 \mathrm{~g}$ of ilmenite particles deteriorates more sharply than for the process with $270 \mathrm{~g}$. The efficiencies 


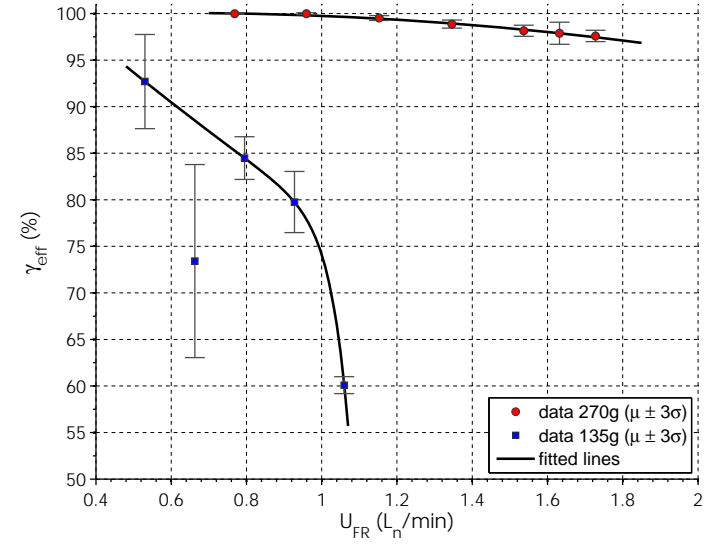

Figure 5: Combustion efficiency for ilmenite experiments at varying fuel flows $\left(T_{\mathrm{FR}}=900^{\circ} \mathrm{C}, U_{\mathrm{AR}}=6.7 \mathrm{~L}_{\mathrm{n}} / \mathrm{min}\right)$

with $270 \mathrm{~g}$ of particles lie entirely above the ones with fewer particles. The sharper decline in combustion efficiency reflects an increased sensitivity towards a change in fuel flow. More particles make the process more robust against changes in fuel flow.

The measured data for $0.66 \mathrm{~L} / \mathrm{min}$ syngas and $135 \mathrm{~g}$ of particles does not seem to fit into the pattern of the other measurements. It is quite probable that the circulation and/or the reactions were somehow not fully established, even though the pressure measurements did not indicate fluidization anomalies. This would also explain the relatively high variance with this setting.

The experiments with varied temperature are shown in two different ways. In Figure 6a, the temperature is varied while the other variables are kept at base settings. Figure $6 \mathrm{~b}$ on the other hand, shows the combustion efficiency as a function of temperature for high and low fuel flows.

The two basic findings from the experiments with varying fuel flow also apply to experiments with varying temperature: the combustion efficiencies dropped significantly from the experiments with $270 \mathrm{~g}$ of ilmenite particles to the ones with $135 \mathrm{~g}$ and the process is more sensitive to changes in variables.

A variation in air flow in the air reactor, as shown in Figure 7, was only investigated during the last part of the experiments with ilmenite, that is, when $135 \mathrm{~g}$ of particles were circulated in the reactor.

Air flow is suspected to affect the circulation rate of the particles. The two main effects of a higher circulation are that the average mass of oxidized oxygen carrier in the fuel reactor is increased and that more oxygen gets into the fuel reactor. Increasing the degree of mass-based conversion $\omega$ by increasing the air flow improves the fuel conversion.

During the initial part of the experiments, i.e. until steam was added to the fuel flow, carbon deposition in the fuel line occurred. The reaction that is believed to be responsible is known as the Boudouard reaction, see equation (14).

$$
2 \mathrm{CO} \rightleftharpoons \mathrm{CO}_{2}+\mathrm{C}
$$

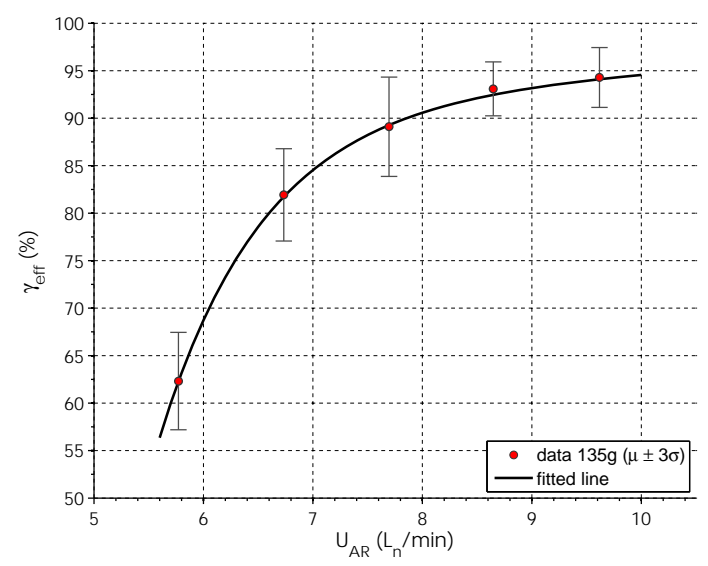

Figure 7: Combustion efficiency for ilmenite experiments at varying air flows (only with $135 \mathrm{~g}$ of particles; $T_{\mathrm{FR}}=900^{\circ} \mathrm{C}, U_{\mathrm{FR}}=$ $0.53 \mathrm{~L}_{\mathrm{n}} / \mathrm{min}$ )

The formation of solid carbon is unwanted for several reasons: it lowers the amount of available carbon and thus adds an error to most of the calculated values; and the reaction of $\mathrm{C}$ and $\mathrm{O}_{2}$ during the reoxidation phase, when air is led to the fuel reactor, is exothermic and could cause thermal damage to certain parts of the fuel inlet.

The amount of carbon that accumulated in the fuel line during one representative experiment was about $0.9 \%$ of the incoming fuel flow. The hydrogen-to-carbon ratio would thus change from 2.00 to 2.02. This error of $1 \%$ occurred during all experiments where no steam was added to the fuel, which basically includes all experiments with $270 \mathrm{~g}$ of ilmenite.

Thermodynamic equilibrium calculations show that $33 \mathrm{vol} \%$ of steam addition is necessary in order to suppress formation of solid carbon. However, it was found that $20 \mathrm{vol} \%$ was sufficient.

The degree to which the particles were reduced in the fuel reactor, i.e. $\omega$, see equation (12), could be estimated with data from reoxidation. The degree of mass-based conversion, $\omega$, for one event was about $96.4 \%$, i.e. $X=28.0 \%$. This number lies well within the expected range of $95 \%$ to $100 \%$, but the uncertainty is high. If, as was discussed earlier, only the iron-rich outer layer of ilmenite oxygen-carrier particles is active, then $X$ would be higher than $100 \%$. This means that the iron oxide in the shell could have been reduced below $\mathrm{Fe}_{3} \mathrm{O}_{4}$. Thermodynamically the reduction from $\mathrm{Fe}_{3} \mathrm{O}_{4}$ to $\mathrm{FeO}$ makes full conversion of syngas to $\mathrm{CO}_{2}$ and $\mathrm{H}_{2} \mathrm{O}$ impossible [13]. However, clear conclusions about how far iron-rich layer and titanium-rich core were reduced cannot be drawn at this moment. It should be mentioned though that if an ilmenite oxygen-carrier is reduced too far, then the conversion of methane or syngas can be impaired.

The circulation of particles was estimated for an air reactor flow of about $7 \mathrm{~L} / \mathrm{min}$ to be in the magnitude of $0.1 \mathrm{~g} / \mathrm{s}$ to $1.0 \mathrm{~g} / \mathrm{s}$ or, when divided by the cross-sectional area of the fuel reactor, about $2 \mathrm{~kg} / \mathrm{s} \mathrm{m}^{2}$ to $20 \mathrm{~kg} / \mathrm{s} \mathrm{m}^{2}$.

A separate analysis was made to compare the reactivity of the particles after $85 \mathrm{~h}$ of operation with that of freshly activated ilmenite, previously examined by Azis et al. [21]. The analysis 


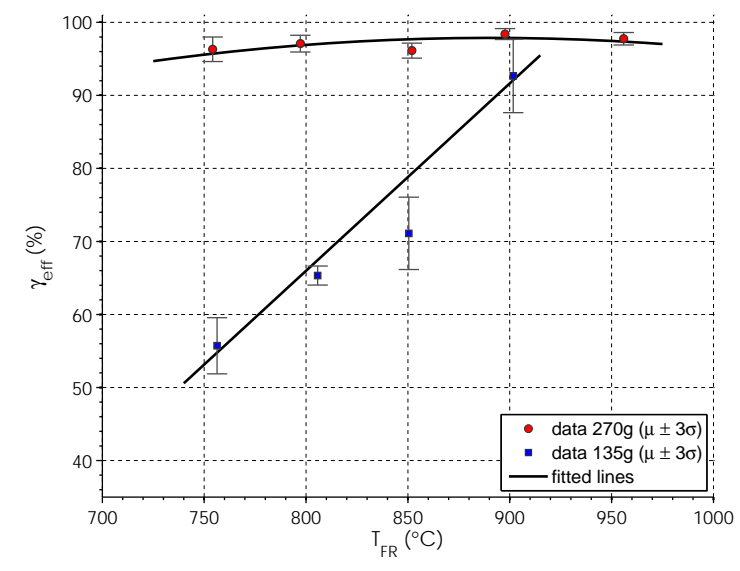

(a) Base parameters $\left(270 \mathrm{~g}: U_{\mathrm{FR}}=1.6 \mathrm{~L} / \mathrm{min}, 135 \mathrm{~g}: U_{\mathrm{FR}}=\right.$ $0.53 \mathrm{~L} / \mathrm{min}$ )

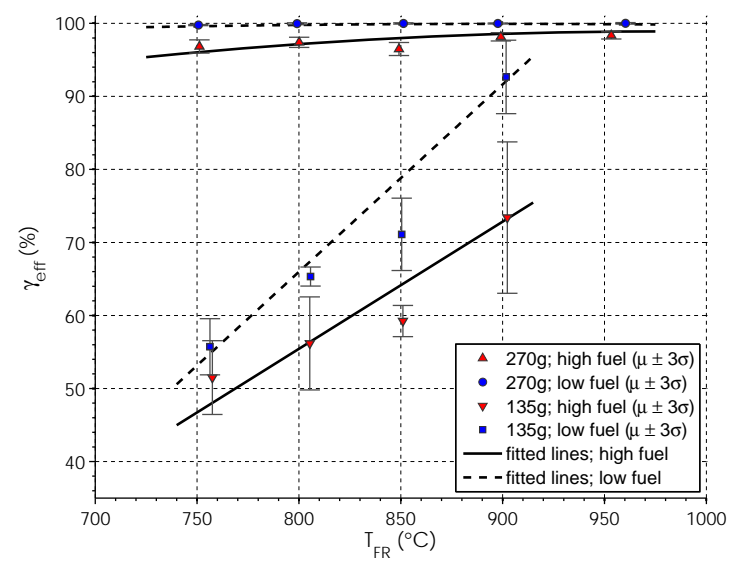

(b) High fuel flow $\left(270 \mathrm{~g}: U_{\mathrm{FR}}=1.5 \mathrm{~L} / \mathrm{min}, 135 \mathrm{~g}: U_{\mathrm{FR}}=\right.$ $\left.0.66 \mathrm{~L}_{\mathrm{n}} / \mathrm{min}\right)$ and low fuel flow $\left(270 \mathrm{~g}: U_{\mathrm{FR}}=0.8 \mathrm{~L}_{\mathrm{n}} / \mathrm{min}\right.$, $\left.135 \mathrm{~g}: U_{\mathrm{FR}}=0.53 \mathrm{~L} \mathrm{n} / \mathrm{min}\right)$

Figure 6: Combustion efficiency for ilmenite experiments at varying temperatures $\left(U_{\mathrm{AR}}=6.7 \mathrm{~L}_{\mathrm{n}} / \mathrm{min}\right)$

was carried out in a batch reactor made of quartz glass and a diameter of $22 \mathrm{~mm} .6 \mathrm{~g}$ of the ilmenite oxygen carrier were mixed with $9 \mathrm{~g}$ of inert quartz sand. At $950^{\circ} \mathrm{C}$, the particles were alternately oxidized with $10 \% \mathrm{O}_{2}$ in nitrogen and reduced by syngas, containing $50 \% \mathrm{CO}$ and $50 \% \mathrm{H}_{2}$. Figure 8 shows the conversion of the two components of syngas, hydrogen and carbon monoxide, as a function of the degree of mass-based conversion $\omega$, see equation (12).

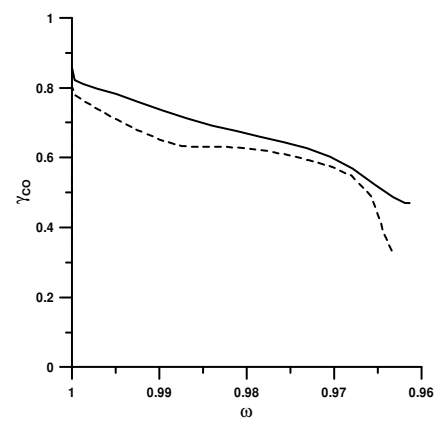

(a) CO conversion

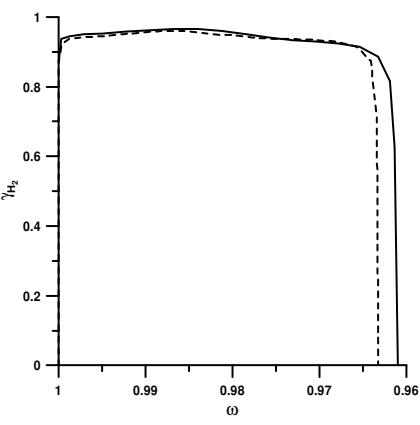

(b) $\mathrm{H}_{2}$ conversion
Figure 8: Gas yield as a function of mass-based conversion to compare reactivity of freshly activated ilmenite oxygen-carrier particles (-) and of oxygen-carrier particles that have been in CLC operation for $85 \mathrm{~h} \mathrm{(---)}$

There is almost no noticeable change in the conversion of $\mathrm{H}_{2}$. The $\mathrm{CO}$ conversion for the used particles is slightly lower than for the freshly activated particles. This means that the overall conversion capability of the ilmenite particles for syngas has not changed in any significant way over the course of the experiments.

In order to visualize the "activation" of the fresh ilmenite particles, the BET surface area was measured. Both BET surface area and bulk density are shown in Figure 9.

It can be seen that the BET surface area increases dramatically in the beginning and then becomes nearly constant. At the

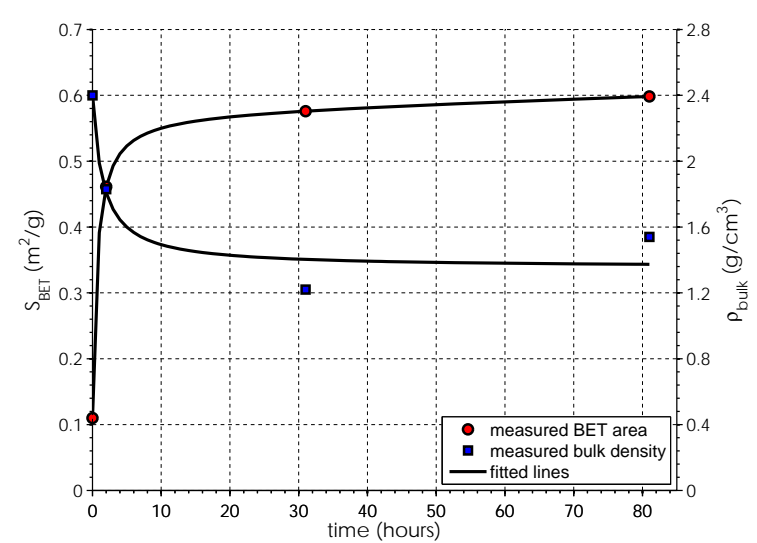

Figure 9: BET surface area and bulk density of ilmenite oxygen-carrier particles throughout the course of $85 \mathrm{~h}$ of CLC operation

same time, the bulk density is reduced in a way that mirrors the growth in the BET surface area, except in the end. The increase in density towards the end of the experiments is also correlated with a reduction in particle size, see Table 4.

\subsection{Iron Oxide Scale}

IOS particles show an increase in reactivity during the initial operating period, see Figure 10. The particle batch during this period consists of $270 \mathrm{~g}$ IOS particles, out of which $72 \%$ had been in previous operation and $28 \%$ were fresh.

After the experiment shown in Figure 10, the degree of mass-based conversion $\omega$ was determined to be $99.1 \%$ ( $X=$ $84.9 \%$ ). Table 6 shows the reference numbers of the reduction $\omega$ and $X$ after different numbers of operational hours. The level of reduction does not change significantly and is generally quite low. The recorded degrees of mass-based conversion stay well below the theoretical maximum reduction of $96.7 \%\left(R_{o}=\right.$ $3.3 \%$ ) for the iron oxide pair $\mathrm{Fe}_{2} \mathrm{O}_{3} / \mathrm{Fe}_{3} \mathrm{O}_{4}$. It is assumed that the oxygen carrier is fully oxidized to $\mathrm{Fe}_{2} \mathrm{O}_{3}$ in the air reactor. 


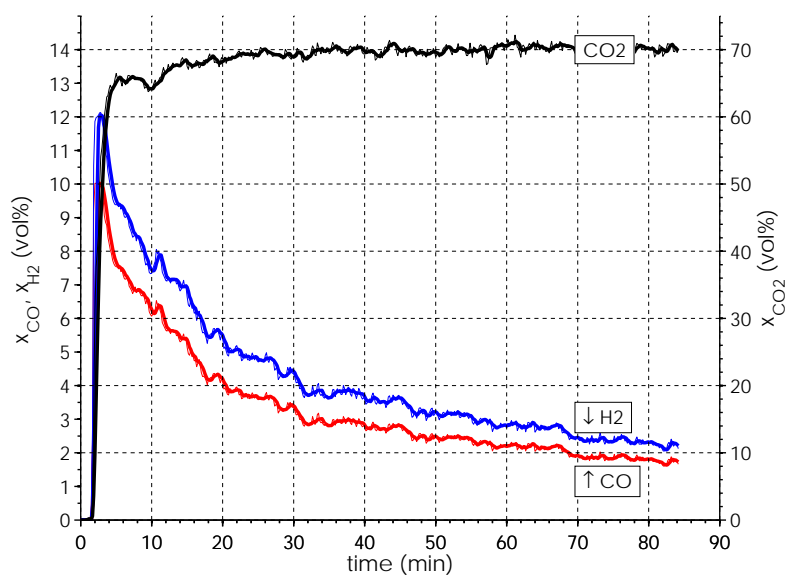

(a) Dry-gas concentrations

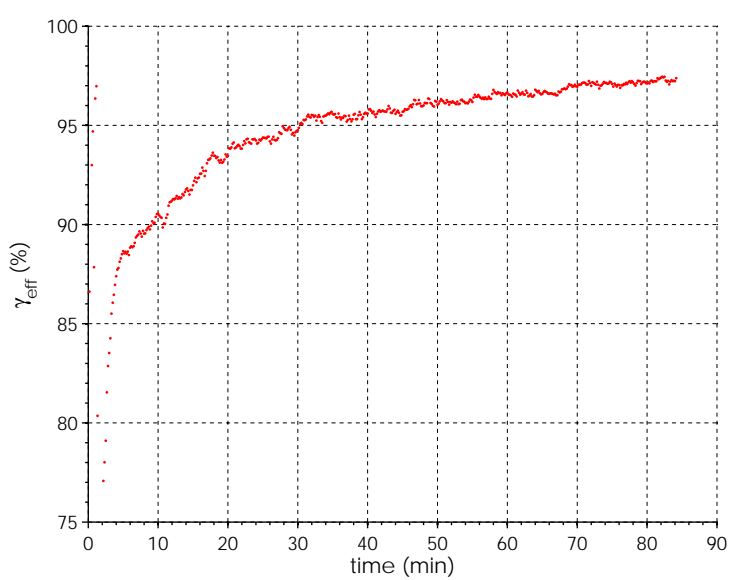

(b) Combustion efficiency

Figure 10: Measurements during the initial operational phase with IOS particles

Hence the IOS oxygen carrier is most probably not reduced below $\mathrm{Fe}_{3} \mathrm{O}_{4}$ and full conversion of syngas to $\mathrm{CO}_{2}$ and $\mathrm{H}_{2} \mathrm{O}$ is thermodynamically possible [13]. Such low degrees of reduction suggest that the particles in the reactor were circulating at a fast rate. The global particle circulation was estimated during a number of occasions. The estimation is based on data from oxygen carrier reoxidization after fuel shut-off at the end of each experiment, the oxygen consumption before fuel was shut-off, and the bed mass in the fuel reactor, see equation (12) and (13). The bed mass is only measured when the reactor is opened, here after $37 \mathrm{~h}$, which means that occasions farther back in time have a higher uncertainty than those closer to $37 \mathrm{~h}$. The global circulation rates for an air reactor flow of $6.7 \mathrm{~L}_{\mathrm{n}} / \mathrm{min}$ were estimated to be about $0.5 \% / \mathrm{s}$ to $1.5 \mathrm{~g} / \mathrm{s}$, which corresponds to about $10 \mathrm{~kg} / \mathrm{s} \mathrm{m}^{2}$ to $20 \mathrm{~kg} / \mathrm{s} \mathrm{m}^{2}$. It was expected that a lowered air reactor flow, as was the case at $26 \mathrm{~h}$, would result in a lower circulation. However, this cannot be seen clearly. It is suspected that changes in particle properties also changed their fluidization properties and thus inhibits further conclusions.

As indicated in Table 7, batch 1, about $6 \%$ of particles escaped the system as fines and the particle size distribution shifted slightly towards smaller diameters. The small change in bulk density must be considered as insignificant. It should be noted that the particles have very irregular shapes and that changes in sphericity could have important effects on the bulk density.

While very little happened to the particles during the first $17 \mathrm{~h}$ of operation, the particle properties changed considerably during the subsequent $20 \mathrm{~h}$. As can be seen in Table 7, batch 2 , the density was significantly reduced and the fraction of finer particles increased considerably. $9 \%$ of the initial particle charge left the system as fines and a total of $34 \%$ was ground to sizes below $90 \mu \mathrm{m}$. There are two possible explanations for the different behavior during the two periods:

1. A process went on from the beginning of the experiments: in the beginning only positive effects of a structural change with increasing porosity were noticed. As the transformation continued, the particles reached a point where they started to break and changes in bulk density and size were observed.

2. During the second operation period the oxygen carrier particles where exposed to conditions, which were different to those of the first operational phase. The maximum fuel flow for example was $40 \%$ higher during the second operation period than during the first. A high fuel flow is usually assumed to cause more reduction, which could have led to the observed changes.

Even though possible, there is no evidence available that would support the first interpretation, e.g. evidence in the form of SEM images or XRD. An unequivocal conclusion explaining the nature of the disintegration of the IOS particles can therefore not be drawn at this moment.

The experiments show that IOS particles are not only likely to form agglomerates, but also have a low structural integrity and become pulverized after a quite short operational period.

Figure 11 shows some selected SEM images of IOS particles at different states. It was found that the particles change from a solid bulky form, as in Figure 11a, to a thin flaky one, such as in Figure 11c. It does not require much imagination to see that those flakes are fragile but might have a greater reactive surface. The XRD shows that there is no visible difference in the chemical structure between fresh material and the used particles: the main component is $\mathrm{Fe}_{2} \mathrm{O}_{3}$ (hematite) with some minor amounts of $\mathrm{SiO}_{2}$ (quartz).

Figure 11d shows an agglomeration and the edge of a gas channel that was formed, which can be seen on the left side of the image. The surface of the channel is smooth, as if the particles had melted and resolidified. The shape of individual particles can no longer be recognized. Figure 11e shows the same agglomerate, but a little further away from the gas channel. The structure here is different: it is still possible to make out the shapes of individual particles, but they appear to be covered by a layer of material that binds them together. The XRD shows that all known oxidization states of iron $\left(\mathrm{Fe}^{0}, \mathrm{Fe}^{2+}, \mathrm{Fe}^{3+}\right)$ are present. From reduced to oxidized, these states occur in metallic iron and three oxides: $\mathrm{Fe}$ (metallic iron) $\rightarrow \mathrm{FeO}$ (wüstite) $\rightarrow$ $\mathrm{Fe}_{3} \mathrm{O}_{4}$ (magnetite) $\rightarrow \mathrm{Fe}_{2} \mathrm{O}_{3}$ (hematite). 
Table 6: Reduction reference numbers $\omega$ and $X$ and oxygen carrier circulation for IOS experiments

\begin{tabular}{|c|c|c|c|c|c|c|c|}
\hline \multirow{2}{*}{$\begin{array}{l}\text { Operation } \\
\text { time }\end{array}$} & \multirow{2}{*}{$\begin{array}{l}\text { Oxygen } \\
\text { consumed }^{1}\end{array}$} & \multirow{2}{*}{$\begin{array}{c}\text { Bed } \\
\text { mass FR }\end{array}$} & \multicolumn{2}{|c|}{ OC reduction ${ }^{1}$} & \multicolumn{2}{|c|}{ OC circulation ${ }^{2}$} & \multirow{2}{*}{$\begin{array}{l}\text { Previous setting } \\
\text { (if differing from base parameters) }\end{array}$} \\
\hline & & & $\omega$ & $X$ & $(\mathrm{~g} / \mathrm{s})$ & $\left(\mathrm{kg} / \mathrm{s} \mathrm{m}^{2}\right)$ & \\
\hline $18.5 \mathrm{~h}$ & $0.93 \mathrm{~g}$ & $103 \mathrm{~g}$ & $99.1 \%$ & $84.9 \%$ & 1.4 & 22 & - \\
\hline $22 \mathrm{~h}$ & $0.93 \mathrm{~g}$ & $103 \mathrm{~g}$ & $99.1 \%$ & $78.6 \%$ & 1.4 & 22 & - \\
\hline $26 \mathrm{~h}$ & $1.24 \mathrm{~g}$ & $103 \mathrm{~g}$ & $98.8 \%$ & $84.9 \%$ & 1.0 & 16 & $U_{\mathrm{AR}}=4.1 \mathrm{~L} / \mathrm{min}$ \\
\hline $30.5 \mathrm{~h}$ & $1.66 \mathrm{~g}$ & $103 \mathrm{~g}$ & $98.4 \%$ & $70.6 \%$ & 0.8 & 13 & $T_{\mathrm{FR}}=950^{\circ} \mathrm{C}$ \\
\hline $33 \mathrm{~h}$ & $1.36 \mathrm{~g}$ & $103 \mathrm{~g}$ & $98.7 \%$ & $79.7 \%$ & 0.9 & 15 & no steam addition \\
\hline $37 \mathrm{~h}$ & $2.71 \mathrm{~g}$ & $103 \mathrm{~g}$ & $97.4 \%$ & $86.3 \%$ & 0.6 & 10 & $U_{\mathrm{FR}}=1.65 \mathrm{~L} / \mathrm{min} ;$ no steam addition \\
\hline
\end{tabular}

Table 7: IOS particle properties of fresh material, after $17 \mathrm{~h}$ and after $37 \mathrm{~h}$ of operation

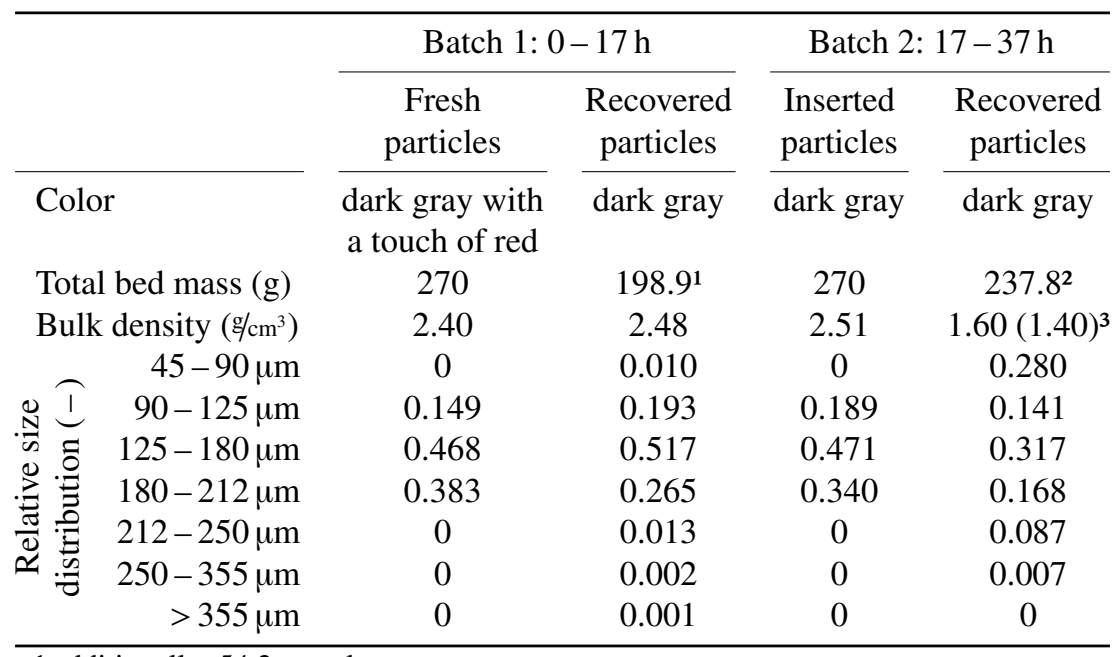

1 additionally: $54.2 \mathrm{~g}$ agglomerates

2 additionally: $7.6 \mathrm{~g}$ agglomerates

${ }^{3}$ with (without) fines $(<90 \mu \mathrm{m})$

The agglomeration of particles might have been triggered by a partial defluidization in the fuel reactor: being defluidized in the bottom zone, they could have become too far reduced and thus agglomerated. Small, local agglomerates could also have grown to form larger ones.

Table 8: XRD analysis of IOS particles

\begin{tabular}{lll}
\hline Particles & & Indicated phases \\
${$\cline { 1 - 1 }$}{ }^{1} }$ & & $\mathrm{Fe}_{2} \mathrm{O}_{3}$ (hematite) \\
After 37 h & & $\mathrm{Fe}_{2} \mathrm{O}_{3}$ (hematite) \\
Agglomerate & $\mathrm{Fe}$ (iron), $\mathrm{FeO}$ (wüstite), \\
& $\mathrm{Fe}_{3} \mathrm{O}_{4}$ (magnetite), $\mathrm{Fe}_{2} \mathrm{O}_{3}$ (hematite) \\
\hline 1 from [9] &
\end{tabular}

Figure 12 shows the experiments where the fuel flow was varied. The trend is that the more fuel is used, the higher the share of unconverted fuel.

What can be seen in Figure 13 is the effect of a variation of the temperature in the reactor. It was varied from the base setting of $900^{\circ} \mathrm{C}$ between the limits of $800{ }^{\circ} \mathrm{C}$ and $950{ }^{\circ} \mathrm{C}$.

The expected behavior is that the process improves with higher temperatures. However, this cannot be seen very clearly. Two factors distort the picture: first, a dip in efficiency can be observed at $850^{\circ} \mathrm{C}$ for all flow levels in Figure 13. This has also been observed with ilmenite oxygen-carrier particles, see section 5.1. However, the reason is not understood. The second peculiarity that strikes out clearly is the decline of combustion efficiency above $900^{\circ} \mathrm{C}$. These exceptions make it difficult to draw an unambiguous conclusion about the temperature behavior of IOS.

\section{Conclusions}

Ilmenite oxygen-carrier particles generally worked well over a long operating period. They are structurally stable and have good fluidization properties. Overall, ilmenite particles produced very promising results.

Initially the particles underwent a considerable alteration process during which they grew bigger, more porous and as a result became more reactive. After this initiation period they were stable in respect of structural stability and reactivity for tens of hours. During the course of experiments it happened on a number of occasions that the particles were reduced to too 


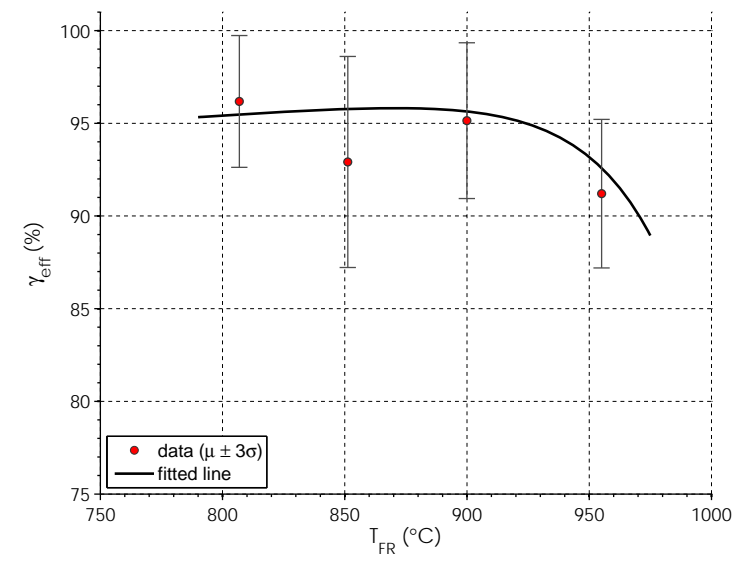

(a) Base parameters $\left(U_{\mathrm{FR}}=1.06 \mathrm{~L}_{\mathrm{n}} / \mathrm{min}\right)$

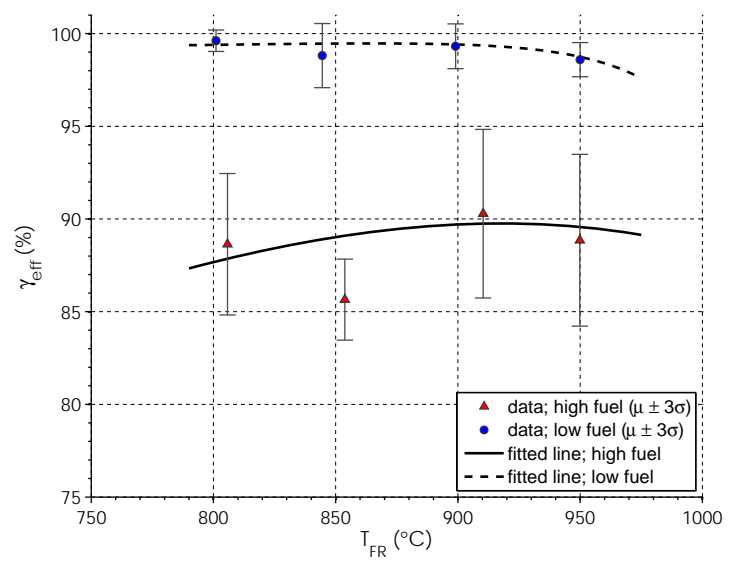

(b) High fuel flow $\left(U_{\mathrm{FR}}=1.59 \mathrm{~L}_{\mathrm{n}} / \mathrm{min}\right)$ and low fuel flow $\left(U_{\mathrm{FR}}=\right.$ $\left.0.53 \mathrm{~L}_{\mathrm{n}} / \mathrm{min}\right)$

Figure 13: Combustion efficiency for IOS experiments at varying temperatures $\left(U_{\mathrm{AR}}=6.7 \mathrm{~L}_{\mathrm{n}} / \mathrm{min}\right)$

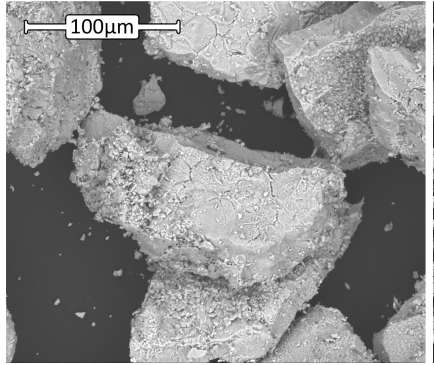

(a) Fresh particles

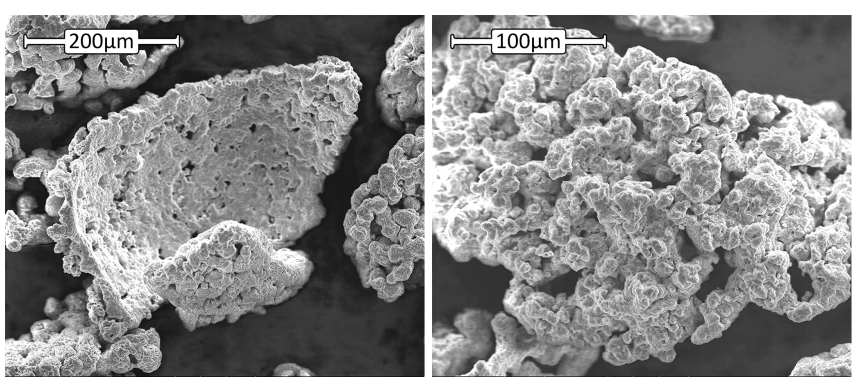

(c) After $37 \mathrm{~h}$

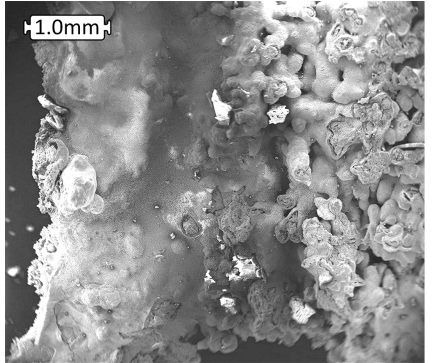

(d) Agglomerate with gas channel

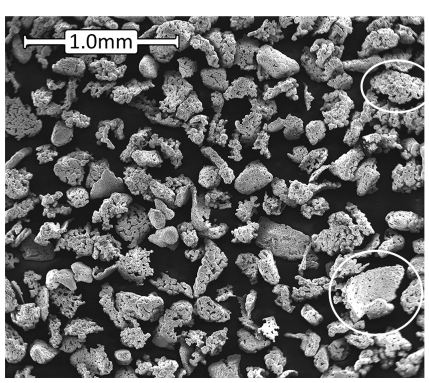

(b) After $37 \mathrm{~h}$

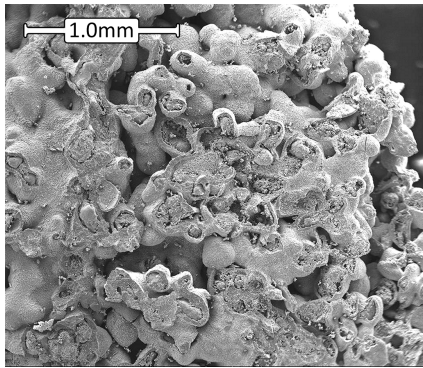

(e) Agglomerated particles
Figure 11: SEM images of fresh, used and agglomerated IOS particles

great an extent over time periods. These were the only incidents when ilmenite was found to form agglomerates. However, these

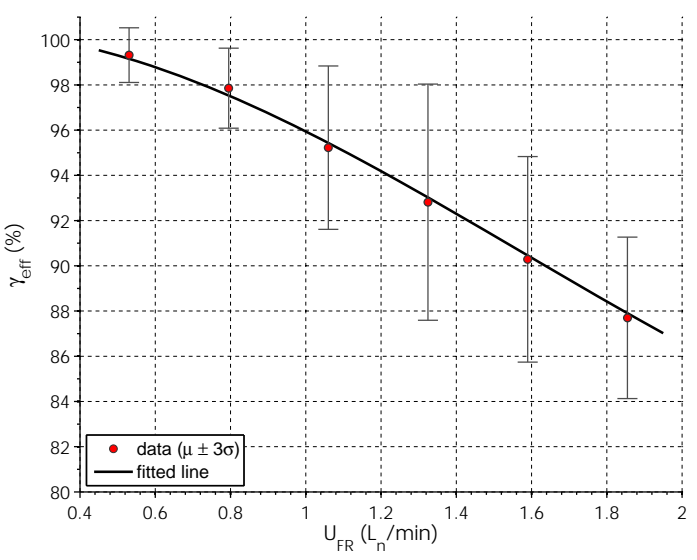

Figure 12: Combustion efficiency for IOS experiments at varying fuel flows $\left(T_{\mathrm{FR}}=900^{\circ} \mathrm{C}, U_{\mathrm{AR}}=6.7 \mathrm{~L}_{\mathrm{n}} / \mathrm{min}\right)$

agglomerates were rather soft and are believed to be little significant - especially when the process is scaled up.

Employing iron oxide scale as an oxygen carrier for chemical-looping combustion is possible but has some difficulties. The biggest problem that was encountered during the experiments was that the particles formed agglomerates in the fuel reactor and fluidization conditions deteriorated or even were inhibited. The agglomerates are believed to originate from particles that are reduced too far. That could either be the case if the residence time in the fuel reactor is generally too long (i.e. a too low global circulation), if particles are trapped in zones of poor circulation (e.g. wall- or corner effects) or if the general mixing level in the fuel reactor is insufficient. All three sources of error can be controlled in bigger reactor systems. Furthermore, the probability that agglomerates can form which cover the whole reactor area of an industrial-sized plant is quite low. Agglomeration as a source of error should be possible to control or suppress in bigger reactor systems.

The rate of attrition for IOS is noticeably higher than for ilmenite. This requires a higher make-up feed and counteracts 
the reduction of the running costs. On the other hand, iron oxide scale is a by-product of the steel-rolling industry and could potentially be cheaper. Both materials are much cheaper than synthesized oxygen carriers.

There are still circumstances which remain unknown and can only be speculated about. Most of these unknown circumstances concern the structural changes of the particles, such as phase migration and structural decay, and fluidizing conditions. Identifying these facts and narrowing down the possibilities is the first step towards understanding the behavior of the particles and thus making processes more predictable.

With comparable settings and about the same bed mass, the fuel conversion with ilmenite particles was clearly better than with IOS particles.

When syngas was used as a fuel, it was found that it caused a deposition of solid carbon in the hot part of the fuel line. This was expected due to the Boudouard reaction and could be overcome by adding steam to the fuel.

It could be shown that a chemical-looping combustion process with the mineral ilmenite and iron oxide scale is possible. Employing minerals and by-product materials as oxygen carriers is a considerable step towards reducing the running costs of a power plant with chemical-looping technology and thus making it more competitive than the existing energy producing technologies. Studying syngas as a fuel is highly relevant for chemical-looping combustion of solid fuels, as syngas is the main product from the gasification of char.

\section{Nomenclature}

\section{Latin symbols}

$\begin{array}{ll}m & {[\mathrm{~kg}]} \\ \dot{m}_{\mathrm{OC}} & {[\mathrm{kg} / \mathrm{s}]} \\ x & {[\mathrm{vol} \%]} \\ y & {[\mathrm{vol} \%]} \\ & \\ H_{i 2} & {\left[\mathrm{~kJ} / \mathrm{m}_{n}^{3}\right]} \\ H / C & {[-]} \\ K_{\mathrm{wgs}} & {[-]} \\ & \\ R_{O} & {[\mathrm{wt} \%]} \\ S_{\mathrm{BET}} & {\left[\mathrm{m}^{2} / \mathrm{g}\right]} \\ T & {\left[{ }^{\circ} \mathrm{C}\right]} \\ U & {\left[\mathrm{~L}_{\mathrm{n}} / \mathrm{min}\right]} \\ X & {[\%]}\end{array}$

mass

oxygen carrier circulation

dry-gas concentration

wet-gas concentration

lower heating value II

hydrogen to carbon ratio

equilibrium constant for the

water-gas shift reaction

oxygen transfer capacity

BET surface area

temperature

volume flow (normalized to $0{ }^{\circ} \mathrm{C}$ )

degree of oxidization

\section{Greek symbols}

$\begin{array}{ll}\gamma_{\text {eff }} & {[\%]} \\ \gamma_{\mathrm{i}} & {[\%]} \\ \mu & \text { varies } \\ \rho_{\text {bulk }} & {\left[\% / \mathrm{cm}^{3}\right]} \\ \sigma & {[-]} \\ \omega & {[\%]}\end{array}$

combustion efficiency

gas yield or conversion of $i$

mean value

bulk density

standard deviation

degree of mass-based conversion

$\begin{array}{ll}\begin{array}{l}\text { Indices } \\ ()_{\mathrm{fm}}\end{array} & \begin{array}{l}\text { fuel mix } \\ \text { at the inlet } \\ ()_{\mathrm{in}}\end{array} \\ \begin{array}{l}\text { most oxidized state } \\ \text { most reduced state }\end{array} \\ ()_{\mathrm{red}} & \text { air reactor } \\ ()_{\mathrm{AR}} & \text { fuel reactor } \\ ()_{\mathrm{FR}} & \begin{array}{l}\text { oxygen carrier } \\ ()_{\mathrm{OC}}\end{array} \\ ()_{\mathrm{PL}} & \text { particle lock(s) }\end{array}$

Acronyms

AR air reactor

CCS

CLC

FR

IOS

SEM

carbon capture and storage

chemical-looping combustion

fuel reactor

iron oxide scale (glödskal)

scanning electron microscope

or microscopy

XRD

\section{Acknowledgements}

The authors would like to thank their co-workers at the Department of Environmental Inorganic Chemistry for carrying out and helping with parts of the experiments.

\section{References}

[1] A. Lyngfelt, M. Johansson, T. Mattisson, Chemical-Looping Combustion - Status of Development, in: 9th International Conference on Circulating Fluidized Beds (CFB-9), Hamburg, Germany, 2008.

[2] M. Hossain, H. de Lasa, Chemical-looping combustion (CLC) for inherent CO2 separations - a review, Chemical Engineering Science 63 (18) (2008) 4433-4451.

[3] H. Fang, L. Haibin, Z. Zengli, Advancements in Development of Chemical-Looping Combustion: A Review, International Journal of Chemical Engineering 2009 (2009) 16.

[4] A. Lyngfelt, Oxygen carriers for chemical-looping combustion - 4000 $\mathrm{h}$ of operational experience, Oil \& Gas Science and Technology 66 (2) (2011) 161-172.

[5] A. Lyngfelt, T. Mattisson, Chemical Looping Materials For CO2 Separation, in: D. Stolten, V. Scherer (Eds.), Efficient Carbon Capture for Coal Power Plants, chap. 17, Wiley-VCH Verlag, Weinheim, first edn., 475504, 2011.

[6] P. den Hoed, A. Luckos, Oxidation and reduction of iron-titanium oxides in chemical looping combustion: A phase-chemical description, Oil \& Gas Science and Technology 66 (2) (2011) 249-263.

[7] H. Leion, A. Lyngfelt, M. Johansson, E. Jerndal, T. Mattisson, The use of ilmenite as an oxygen carrier in chemical-looping combustion, Chemical Engineering Research and Design 86 (2008) 1017-1026.

[8] J. Adánez, A. Cuadrat, A. Abad, P. Gayán, L. de Diego, F. GarcíaLabiano, Ilmenite activation during consecutive redox cycles in chemicallooping combustion, Energy \& Fuels 24(2) (2010) 1402-1413.

[9] H. Leion, Capture of $\mathrm{CO}_{2}$ from solid fuels using Chemical-Looping Combustion and Chemical-Looping Oxygen Uncoupling, Ph.D. thesis, Chalmers University of Technology, Göteborg, Sweden, 2008.

[10] H. Leion, T. Mattisson, A. Lyngfelt, Use of Ores and Industrial Products As Oxygen Carriers in Chemical-Looping Combustion, Energy \& Fuels 23 (2009) 2307-2315.

[11] M. Rydén, M. Johansson, E. Cleverstam, A. Lyngfelt, T. Mattisson, Ilmenite with addition of $\mathrm{NiO}$ as oxygen carrier for chemical-looping combustion, Fuel 89 (11) (2010) 3523-3533. 
[12] M. Johansson, T. Mattisson, A. Lyngfelt, Investigation of $\mathrm{Fe}_{2} \mathrm{O}_{3}$ with $\mathrm{MgAl}_{2} \mathrm{O}_{4}$ for chemical-looping combustion, Industrial \& Engineering Chemistry Research 43 (2004) 6978-6987.

[13] E. Jerndal, T. Mattisson, A. Lyngfelt, Thermal analysis of chemicallooping combustion, Chemical Engineering Research and Design 84(A9) (2006) 795-806.

[14] P. Cho, T. Mattisson, A. Lyngfelt, Defluidization conditions for a fluidized bed of iron oxide-, nickel oxide-, and manganese oxide-containing oxygen carriers for chemical-looping combustion, Industrial \& Engineering Chemistry Research 45(3) (2006) 968-977.

[15] M. Johansson, Screening of oxygen-carrier particles based on iron-, manganese-, copper- and nickel oxides for use in chemical-looping technologies, Ph.D. thesis, Chalmers University of Technology, Göteborg, Sweden, 2007.

[16] N. Berguerand, A. Lyngfelt, Design and operation of a $10 \mathrm{~kW}_{\text {th }}$ chemicallooping combustor for solid fuels - Testing with South African coal, Fuel 87 (2008) 2713-2726.

[17] P. Cho, T. Mattisson, A. Lyngfelt, Comparison of iron-, nickel-, copper-, and manganese-based oxygen carriers for chemical-looping combustion, Fuel 83 (2004) 1215-1225.

[18] D. Bhogeswara Rao, M. Rigaud, Kinetics of the oxidation of ilmenite, Oxidation of Metals 9 (1) (1975) 99-116.

[19] J. Nell, An overview of the phase-chemistry involved in the production of high-titanium slag from ilmenite feedstock, in: R. Stimson (Ed.), Proceedings of Heavy Minerals, Symposium series S23, The South African Institute of Mining and Metallurgy, Johannesburg, 137-145, 1999.

[20] E. Jerndal, H. Leion, L. Axelsson, T. Ekvall, M. Hedberg, K. Johansson, M. Källén, R. Svensson, T. Mattisson, A. Lyngfelt, Using low-cost ironbased materials as oxygen carriers for chemical looping combustion, Oil \& Gas Science and Technology 66 (2) (2011) 235-248.

[21] M. M. Azis, E. Jerndal, H. Leion, T. Mattisson, A. Lyngfelt, On the evaluation of synthetic and natural ilmenite using syngas as fuel in chemicallooping combustion (CLC), Chemical Engineering Research and Design 88 (11) (2010) 1505-1514. 